\title{
Influência da heparina sódica na ocorrência de laminite eqüina induzida por sobrecarga de carboidratos
}

[Influence of heparin in occurrence of carbohydrate overload-induced equine laminitis]

\author{
L.P. Martins Filho ${ }^{1}$, J.J. Fagliari ${ }^{*}$, J.R.E. Moraes ${ }^{2}$, R.C. Sampaio ${ }^{1}$, J.A. Oliveira $^{2}$, J.C. Lacerda Neto ${ }^{2}$ \\ ${ }^{1}$ Centro Universitário de Rio Preto - UNIRP - São José do Rio Preto, SP \\ ${ }^{2}$ Faculdade de Ciências Agrárias e Veterinárias - UNESP \\ Via de Acesso Prof. Paulo Donato Castellane, s/n \\ 14884-900 - Jaboticabal, SP
}

\begin{abstract}
RESUMO
Avaliou-se a eficiência da infusão intravenosa de heparina sódica $(100 \mathrm{UI} / \mathrm{kg} / 8 \mathrm{~h}$, a partir de $24 \mathrm{~h}$ após o fornecimento de carboidrato, até completar $48 \mathrm{~h}$ ) no controle da laminite eqüina experimentalmente induzida por sobrecarga de carboidrato (17,6g de amido de milho/kg de peso corpóreo). Foram utilizados 15 eqüinos adultos, distribuídos em três grupos experimentais: GI (grupo-controle); GII (grupo laminite) e GIII (grupo laminite+heparina). Posteriormente ao fornecimento de carboidrato, os animais foram submetidos a exames físicos e laboratoriais durante um período de 48 horas. Ao final do experimento, os animais foram submetidos à eutanásia pela aplicação intravenosa de $5 \mathrm{ml}$ de maleato de acepromazina seguida de $1 \mathrm{~g}$ de tiopental sódico e 1 litro de solução saturada de $\mathrm{KCl}$ para a obtenção de amostras de tecidos dos cascos, necessárias ao exame histológico. Os animais de GII e GIII, submetidos à sobrecarga de carboidratos, desenvolveram laminite, exibindo claudicação 12 e $24 \mathrm{~h}$ após o fornecimento de carboidrato, respectivamente, bem como aumentos da freqüência cardíaca e do tempo de preenchimento capilar. As alterações histológicas, semelhantes em GII e GIII, eram do tipo degenerativo, como adelgaçamento de lâminas epidérmicas, retração, achatamento e deslocamento de lâminas dérmicas, vacuolização epidérmica e desorganização do tecido epidérmico. A infusão da heparina sódica não preveniu ou atenuou a degeneração laminar.
\end{abstract}

Palavras-chave: eqüino, laminite, carboidrato, heparina

\begin{abstract}
The efficacy of intravenous heparin administration (100UI/kg/8h, from 24 to $48 \mathrm{~h}$ after carbohydrate administration) in the control of carbohydrate overload-induced equine laminitis (17.6g of corn starch $/ \mathrm{kg}$ live weight) was evaluated. Fifteen horses were allocated into three experimental groups: GI (control group), GII (laminitis group), and GIII (laminitis+heparin group). These animals were submitted to physical and laboratorial examination during 48h. After that time, they were euthanized with intravenous administration of $5 \mathrm{ml}$ of acepromazine followed by $1 \mathrm{~g}$ of thiopental sodium and 1 liter of saturated solution of $\mathrm{KCl}$ to obtain hoof tissues samples for histological examination. GII and GIII horses developed laminitis, showing lameness 12 and $24 \mathrm{~h}$ after carbohydrate administration, respectively, as well increased heart rate and capillary refill time. The histological alterations, similar in GII and GIII, were degenerative lesions, as thinness of epidermal lamina, retraction, flattening and dislocation of the dermal lamina, epidermal vacuolization, and disruption of the epidermal tissues. The occurrence of laminar degeneration was not prevented or attenuated with intravenous heparin administration.
\end{abstract}

Keywords: equine, laminitis, carbohydrate, heparin

Recebido em 27 de agosto de 2007

Aceito em 24 de setembro de 2008

*Autor para correspondência (corresponding author)

E-mail: fagliari@fcav.unesp.br 


\section{INTRODUÇÃO}

Apesar dos avanços no entendimento da fisiopatogenia da laminite eqüina, vários animais ainda padecem dessa afecção, considerada uma das principais causas de claudicação em eqüinos (Moore et al., 1989; Baxter, 1994). A complexidade da patogênese torna o tratamento difícil e oneroso e a doença freqüentemente evolui para um quadro grave e, às vezes, morte do animal. Vários são os fatores envolvidos no desenvolvimento de laminite, com destaque para as disfunções gastrintestinais, hipoperfusão periférica, endotoxemia e aumento sistêmico e local das concentrações de citocinas próinflamatórias, capazes de aumentar a atividade das metaloproteinases no tecido conectivo (Johnson et al., 2000). Esses eventos são acompanhados de elevação nas concentrações de proteínas de fase aguda no soro sangüíneo (Fagliari et al., 1998).

A absorção intestinal de endotoxinas e ou de ácido láctico é responsável pela ocorrência de lesões vasculares no casco, três a quatro horas após a administração de alta dose de carboidratos (Eades et al., 2006). Esses autores também verificaram lesões microscópicas nos intestinos, especialmente no ceco, após o fornecimento de carboidrato. Lesões da mucosa intestinal aumentam sua permeabilidade, permitindo absorção de endotoxinas e, conseqüentemente, choque endotoxêmico e/ou séptico (Garner et al., 1975; Weiss et al., 1997a). Aumento marcante e transitório de permeabilidade intestinal foi detectado no início do estágio prodrômico da laminite alimentar, porém sem detecção de sinais consistentes de endotoxemia (Weiss et al., 1994; Weiss et al., 1995).

Várias hipóteses foram aventadas para explicar a hipoperfusão laminar com base nos efeitos induzidos pelas endotoxinas, como microtrombose, vasoconstrição ou desvio de sangue por anastomoses arteriovenosas (Moore et al., 1989; Bailey et al., 2004). Microtrombose tem sido implicada como o evento inicial na patogênese da hipoperfusão observada na laminite (Weiss et al., 1994). Segundo os autores, embora a contagem de plaquetas permaneça inalterada, ocorre diminuição em sua sobrevida oito horas após a administração de carboidratos, ou seja, 24 horas antes do início da claudicação. A ocorrência de microtrombose na muralha do casco foi avaliada por cintigrafia e histologia e detectou-se um acúmulo de plaquetas no local (Weiss et al., 1995). A ativação de plaquetas induzida por endotoxinas depende do fator de agregação plaquetária (PAF), sintetizado nas células epiteliais da mucosa intestinal e nos neutrófilos, em resposta à ação de endotoxinas ou de outras citocinas. Esses autores consideram que lesões na mucosa intestinal podem estimular a secreção de PAF, induzindo à ativação e agregação de plaquetas $\mathrm{e}$ neutrófilos. Esses agregados podem se instalar na muralha dos cascos e originar microtrombos, em razão da alta resistência venosa associada à elevação da pressão hidrostática (Weiss et al., 1997b). Estudos in vitro mostraram redução na deformabilidade do agregado plaquetaneutrófilo, evento que pode alterar o fluxo sanguíneo na microvasculatura (Weiss et al., 1999).

Segundo (Hood et al., 1993), no dígito de cavalo com laminite aguda notam-se angiopatia e distorção mecânica do tecido dérmicoepidérmico, sendo a angiopatia o evento histológico inicial. Pollitt (1996) relatou a desintegração da membrana basal e defeito na junção das células basais da epiderme como um dos eventos patológicos mais precoces da laminite aguda. Esse autor propôs a classificação histopatológica das lesões, de acordo com a sua gravidade, em normal (grau N), discreta (grau 1), moderada (grau 2) e grave (grau 3) baseando-se, principalmente, nas alterações da membrana basal. A membrana basal, composta de proteínas colagenosas, como o colágeno tipo IV, e de proteínas não-colagenosas, como proteoglicans e glicoproteínas, das quais a principal é a laminina, é degradada por metaloproteinases (Johnson et al., 2000). Pollitt (1999) considerou a ativação descontrolada de metaloproteinases como importante evento na patogênese da laminite.

A heparina foi indicada na prevenção de laminite experimental (Cohen et al., 1994). Segundo Hood et al. (1982), a heparina previne laminite induzida por carboidrato, mas é menos efetiva em casos de ocorrência natural. Entretanto, a administração de heparina induz aglutinação de hemácias, anemia e trombocitopenia temporárias (Weiss et al., 1997a).

Assim, os objetivos deste estudo foram determinar a eficiência da infusão intravenosa de 
100UI de heparina sódica $/ \mathrm{kg}$ de peso do animal na fase prodrômica da laminite e avaliar as alterações clínicas e laboratoriais, inclusive a histologia.

\section{MATERIAL E MÉTODOS}

Foram utilizados 15 eqüinos adultos, sem raça definida, machos e fêmeas clinicamente sadios, entre quatro e nove anos de idade e pesos entre 310 e $512 \mathrm{~kg}$, distribuídos em três grupos. No grupo I (controle) usaram-se cinco animais alimentados com feno e água à vontade; no grupo II, denominado grupo laminite, utilizaramse cinco animais que, após jejum de 12 horas, receberam solução composta de $17,6 \mathrm{~g}$ de amido de milho $^{1}$ por $\mathrm{kg}$ de peso corpóreo (PC), dissolvidos em água, na proporção de $1 \mathrm{~kg}: 1$ litro, mediante uso de sonda nasogástrica; e no grupo III, denominado grupo laminite+heparina, cinco animais submetidos ao mesmo tratamento do grupo II. A estes, administraram-se, por via intravenosa, 100UI de heparina sódica/kg PC, em intervalos de oito horas, a partir de 24 horas após o fornecimento de carboidratos, até completar 48 horas.

Foram realizados exames físicos (Speirs, 1996) e laboratoriais em seis momentos: antes da administração de carboidratos e oito, 12, 24, 36 e 48 horas após. Os eqüinos do grupo I foram submetidos aos mesmos procedimentos. Foram avaliadas freqüências cardíaca (FC) e respiratória (FR), temperatura retal (TR), tempo de preenchimento capilar (TPC), qualidade do pulso da artéria maxilar externa (PAME) e da artéria digital do membro torácico direito (PADMTD), grau de claudicação (Obel, 1948) e motilidade intestinal (MI). A detecção do pulso sob um único dígito, considerado fraco, recebeu grau 0 ; quando a pressão era percebida sob dois dedos era considerada moderada e classificada como grau 1; a graduação 2 referia-se à sensibilidade sob os três dedos; e o grau 3 quando o pulso era imperceptível. A motilidade intestinal foi classificada como grau 0 quando havia hipomotilidade; grau 1 para motilidade normal; e grau 2 quando detectou-se hipermotilidade.

As amostras de sangue foram colhidas mediante punção da veia jugular e acondicionadas em um

\footnotetext{
${ }^{1}$ Maizena - Refinações de Milho Brasil Ltda, Mogi GuaçuSP
}

tubo sem anticoagulante, destinadas ao perfil bioquímico sérico, e em outro com ácido etilenodiaminotetracético (EDTA) $10 \%$, para o hemograma, dosagem de fibrinogênio e de proteína total, por refratometria.

Os eqüinos foram submetidos à eutanásia, 48 horas após a administração da solução de amido, por meio da administração intravenosa de $5 \mathrm{ml}$ de acepromazia $^{2}$, seguida de $1 \mathrm{~g}$ de tiopental sódico ${ }^{3}$ e 1 litro de solução saturada de $\mathrm{KCl}$. Os cascos foram removidos e seccionados de acordo com a recomendação de Pollitt (1996). As secções de tecido foram submetidas ao exame histológico (Weiss et al., 1994).

Para análise estatística utilizou-se o programa SAS (User's..., 1995). Quando se constatou significância entre grupos e momentos aplicou-se o teste Tukey para comparação das médias $(\mathrm{P}<0,05)$.

\section{RESULTADOS}

Os resultados das avaliações clínicas e dos exames laboratoriais são apresentados nas Tab. 1 e 2 , respectivamente.

No exame histológico, notou-se que as secções de tecido dos cascos dos animais do grupo I mantiveram a preservação da arquitetura morfológica. Nos animais do grupo II, nos cortes histológicos foram verificadas alterações indicativas de degeneração laminar. As lâminas epidérmicas primárias (LEP) encontravam-se onduladas, indicando retração, e os ápices das vilosidades ou criptas apresentavam-se afilados; nos eixos ceratinizados notou-se desalinhamento das fibras de colágeno. As lâminas epidérmicas secundárias (LES) mostraram-se adelgaçadas, alongadas, onduladas e com ápices pontiagudos, muitas delas perpendiculares ao eixo ceratinizado das LEP. Retração de LES foi observada, com freqüência, na porção basal e no terço médio das LEP. Os núcleos das células basais (CB) perderam sua forma ovalada e apresentavam-se arredondados, escuros e pequenos, bem próximos à membrana basal (MB). O citoplasma das CB mostrou-se róseoclaro quando corado pela hematoxilina e eosina, heterogêneo e vacuolizado. Várias $\mathrm{CB}$ eram

\footnotetext{
${ }^{2}$ Acepran 1\%, Laboratório Univet-SP

${ }^{3}$ Tiopental, Laboratório Cristália-SP
} 
desprovidas de núcleo e várias lâminas epidérmicas estavam desprovidas de $\mathrm{CB}$, notando-se apenas resquício de núcleo. Em diversas secções, nos animais desse grupo, não havia anatomia lamelar simétrica regular e embora houvesse muitos núcleos picnóticos na estrutura epidérmica, vários pareciam intactos, indicando diferentes graus de lesões degenerativas. Ocasionalmente, na derme sublamelar foram identificados vasos sangüíneos, inclusive capilares, contendo material proteináceo amorfo, corado em rosa, indicando trombose. Outras alterações circulatórias, como congestão vascular, hemorragias, células inflamatórias ao redor de vasos ou no ápice das LEP foram constatadas em algumas secções. Nas secções coradas com ácido periódico de Schiff (PAS) foi notória a assimetria de MB. A MB, uma linha PASpositiva, apresentou contorno ondulado e, às vezes, descontínuo, principalmente na base da LES. Algumas LES apresentaram aumento de volume em seus ápices, lembrando uma bolha.

Nos animais do grupo III as alterações morfológicas foram indistinguíveis das observadas nos animais do grupo II, descritas anteriormente.

Tabela 1. Média e desvio-padrão dos parâmetros clínicos de eqüinos segundo os tratamentos e o tempo de fornecimento do carboidrato

\begin{tabular}{|c|c|c|c|c|c|c|}
\hline \multirow{2}{*}{ Parâmetro } & \multicolumn{6}{|c|}{ Tempo após o fornecimento de carboidratos (h) } \\
\hline & 0 & 8 & 12 & 24 & 36 & 48 \\
\hline \multicolumn{7}{|l|}{ FC/min } \\
\hline G 1 & $39,6 \pm 2,1 \mathrm{Aa}$ & $46,8 \pm 7,5 \mathrm{Aa}$ & $36,0 \pm 3,1 \mathrm{Aa}$ & $37,2 \pm 5,4 \mathrm{Aa}$ & $40,0 \pm 4,6 \mathrm{Aa}$ & $32,8 \pm 3,0 \mathrm{Aa}$ \\
\hline G 2 & $52,0+10,4 \mathrm{Aa}$ & $49,2+5,0 \mathrm{Aa}$ & $44,0+8,3 \mathrm{Aa}$ & $43,6+6,9 \mathrm{Aab}$ & $74,8+26,1 \mathrm{Bb}$ & $82,4+7,2 \mathrm{Bb}$ \\
\hline G 3 & $39,0 \pm 3,0 \mathrm{Aa}$ & $42,0 \pm 3,7 \mathrm{Aa}$ & $46,8 \pm 6,2 \mathrm{Aa}$ & $58,8 \pm 4,8 \mathrm{Ab}$ & $81,2 \pm 14,8 \mathrm{Bb}$ & $82,8 \pm 13,9 \mathrm{Bb}$ \\
\hline \multicolumn{7}{|l|}{$\mathrm{FR} / \mathrm{min}$} \\
\hline G 1 & $9,6 \pm 2,6$ & $14,8 \pm 2,2$ & $12,4 \pm 1,6$ & $11,2 \pm 1,0$ & $12,8 \pm 1,7$ & $12,40 \pm 1,67$ \\
\hline G 2 & $16,4 \pm 6,6$ & $17,2+4,6$ & $14,0 \pm 5,1$ & $10,8+3,0$ & $17,20+5,76$ & $15,20 \pm 3,03$ \\
\hline G 3 & $11,6 \pm 2,6$ & $21,6+4,3$ & $18,8 \pm 7,9$ & $17,2+5,7$ & $20,80 \pm 16,47$ & $21,60 \pm 11,08$ \\
\hline \multicolumn{7}{|l|}{$\mathrm{TR}\left({ }^{\circ} \mathrm{C}\right)$} \\
\hline G 1 & $37,1 \pm 0,3 \mathrm{Aa}$ & $38,1 \pm 0,2 \mathrm{Aa}$ & $38,5 \pm 0,05 \mathrm{Aa}$ & $37,4 \pm 0,08 \mathrm{Aa}$ & $38,20 \pm 1,19 \mathrm{Aa}$ & $37,1+0,18 \mathrm{Aa}$ \\
\hline G 2 & $37,6 \pm 0,5 \mathrm{ACa}$ & $38,0 \pm 0,4 \mathrm{ACa}$ & $38,4 \pm 0,29 \mathrm{Ca}$ & $36,2 \pm 3,48$ & $40,70 \pm 0,87 \mathrm{Bb}$ & $39,7 \pm 1,31 \mathrm{BCb}$ \\
\hline G 3 & $37, \overline{6}+0,4 \mathrm{Aa}$ & $38,6 \pm 0,5 \mathrm{ACa}$ & $39,0 \pm 0,9 \mathrm{ACa}$ & $40,1 \pm 0,74 \mathrm{BCb}$ & $40,1 \pm 0,79 \mathrm{BCab}$ & $39,8 \pm 0,45 \mathrm{BCb}$ \\
\hline \multicolumn{7}{|l|}{ TPC/seg } \\
\hline G 1 & $3,0 \pm 0,01 \mathrm{Aa}$ & $2,6 \pm 0,5 \mathrm{Aa}$ & $2,80 \pm 0,45 \mathrm{Aa}$ & $2,40 \pm 0,55 \mathrm{Aa}$ & $2,40 \pm 0,55 \mathrm{Aa}$ & $2,40 \pm 0,55 \mathrm{Aa}$ \\
\hline G 2 & $2,40 \pm 0,55 \mathrm{Aa}$ & $2,8 \pm 0,4 \mathrm{Aa}$ & $2,80 \pm 0,45 \mathrm{Aa}$ & $3,0 \pm 0,71 \mathrm{Aa}$ & $3,60 \pm 0,55 \mathrm{Aa}$ & $3,60 \pm 0,55 \mathrm{Aa}$ \\
\hline G 3 & $2,60 \pm 0,55 \mathrm{Aa}$ & $2,8 \pm 0,4 \mathrm{ABab}$ & $3,0 \pm 0,7 \mathrm{ABab}$ & $3,0 \pm 1,0 \mathrm{ABab}$ & $4,00 \pm 1,58 \mathrm{Bb}$ & $3,8 \pm 1,30 \mathrm{ABab}$ \\
\hline \multicolumn{7}{|l|}{ PAME } \\
\hline G 1 & $0,20 \pm 0,45$ & $0,40 \pm 0,55$ & $0,80 \pm 0,45$ & $0,40 \pm 0,55$ & $0,60 \pm 0,55$ & $0,60 \pm 0,55$ \\
\hline G 2 & $0,0 \pm 0,0$ & $0,20 \pm 0,45$ & $0,20 \pm 0,45$ & $0,80 \pm 1,09$ & $1,00 \pm 0,71$ & $1,00 \pm 0,71$ \\
\hline G 3 & $0,0 \pm 0,0$ & $0,80 \pm 0,45$ & $1,20 \pm 0,84$ & $1,20 \pm 0,84$ & $0,80 \pm 1,09$ & $0,60 \pm 0,89$ \\
\hline \multicolumn{7}{|l|}{ PADMTD } \\
\hline G 1 & $0,0 \pm 0,0 \mathrm{Aa}$ & $0,40 \pm 0,55 \mathrm{Aa}$ & $0,0 \pm 0,0 \mathrm{Aa}$ & $0,0 \pm 0,0 \mathrm{Aa}$ & $0,20 \pm 0,45 \mathrm{Aa}$ & $0,0 \pm 0,0 \mathrm{Aa}$ \\
\hline G 2 & $0,0 \pm 0,0 \mathrm{Aa}$ & $0,0 \pm 0,0 \mathrm{Aa}$ & $0,20 \pm 0,45 \mathrm{Aa}$ & $0,40 \pm 0,55 \mathrm{Aa}$ & $1,00 \pm 1,0 \mathrm{ABa}$ & $1,60 \pm 0,55 \mathrm{Bb}$ \\
\hline G 3 & $0,0 \pm 0,0 \mathrm{Aa}$ & $0,80 \pm 0,84 \mathrm{Aa}$ & $0,60+0,55 \mathrm{Aa}$ & $0,20 \pm 0,45 \mathrm{Aa}$ & $0,40 \pm 0,55 \mathrm{Aa}$ & $0,80 \pm 0,84 \mathrm{Aab}$ \\
\hline \multicolumn{7}{|l|}{ OBEL } \\
\hline G 1 & $0,0 \pm 0,0 \mathrm{Aa}$ & $0,0 \pm 0,0 \mathrm{Aa}$ & $0,0+0,0 \mathrm{Aa}$ & $0,0 \pm 0,0 \mathrm{Aa}$ & $0,0 \pm 0,0 \mathrm{Aa}$ & $0,0 \pm 0,0 \mathrm{Aa}$ \\
\hline G 2 & $0,0 \pm 0,0 \mathrm{Aa}$ & $0,0 \pm 0,0 \mathrm{Aa}$ & $0,40+0,55 \mathrm{Aa}$ & $0,80 \pm 0,45 \mathrm{Aab}$ & $2,80 \pm 0,45 \mathrm{Bb}$ & $3,60 \pm 0,55 \mathrm{Bb}$ \\
\hline G 3 & $0,0 \pm 0,0 \mathrm{Aa}$ & $0,0 \pm 0,0 \mathrm{Aa}$ & $0,0 \pm 0,0 \mathrm{Aa}$ & $1,20 \pm 0,45 \mathrm{Cb}$ & $2,20 \pm 0,84 \mathrm{Bb}$ & $2,80 \pm 1,30 \mathrm{Bb}$ \\
\hline \multicolumn{7}{|l|}{ MI } \\
\hline G 1 & $1,0 \pm 0,0$ & $1,0 \pm 0,0$ & $1,0 \pm 0,0$ & $1,20 \pm 0,45$ & $1,00 \pm 0,00$ & $1,00 \pm 0,00$ \\
\hline G 2 & $1,0 \pm 0,0$ & $1,0 \pm 0,0$ & $1,0 \pm 0,71$ & $1,40 \pm 0,55$ & $1,20 \pm 0,84$ & $0,60 \pm 0,89$ \\
\hline G 3 & $1,0 \pm 0,0$ & $1,4 \pm 0,5$ & $2,00 \pm 0,0$ & $1,00 \pm 0,71$ & $1,40 \pm 0,89$ & $0,80 \pm 0,84$ \\
\hline
\end{tabular}

GI: grupo controle; GII: grupo tratado com 17,6g de amido de milho; GIII: idem ao GII + administração de heparina; FC: freqüência cardíaca; FR: freqüência respiratória; TR: temperatura retal; TCP: tempo de preenchimento capilar; PAME: qualidade do pulso da artéria maxilar externa; PADMTD: qualidade do pulso da artéria digital do membro torácico direito; OBEL: grau de claudicação; MI: motilidade intestinal.

Letras maiúsculas diferentes indicam diferenças entre grupos pelo teste Tukey $(\mathrm{P}<0,05)$.

Letras minúsculas diferentes indicam diferenças entre momentos pelo teste Tukey $(\mathrm{P}<0,05)$. 
Tabela 2. Média e desvio-padrão do hemograma de eqüinos segundo os tratamentos e o tempo de fornecimento do carboidrato

\begin{tabular}{|c|c|c|c|c|c|c|}
\hline \multirow{2}{*}{ Parâmetro } & \multicolumn{6}{|c|}{ Tempo após o fornecimento de carboidratos (h) } \\
\hline & 0 & 8 & 12 & 24 & 36 & 48 \\
\hline \multicolumn{7}{|l|}{$\begin{array}{l}\mathrm{He} / \mu \mathrm{l} \\
\left(\mathrm{x} 10^{6}\right)\end{array}$} \\
\hline G 1 & $6,80 \pm 0,71$ & $6,60 \pm 0,46$ & $6,60 \pm 0,43$ & $6,20 \pm 0,47$ & $6,80 \pm 0,49$ & $6,70 \pm 0,24$ \\
\hline G 2 & $7,50 \pm 0,94$ & $7,00 \pm 0,83$ & $7,30 \pm 0,34$ & $7,30 \pm 0,81$ & $7,50 \pm 0,79$ & $7,90 \pm 0,56$ \\
\hline G 3 & $7,40 \pm 0,69$ & $6,80 \pm 0,74$ & $7,20 \pm 0,33$ & $7,20 \pm 1,02$ & $6,80 \pm 0,53$ & $6,90 \pm 0,68$ \\
\hline \multicolumn{7}{|l|}{$\mathrm{Hb}(\mathrm{g} / \mathrm{dl})$} \\
\hline G 1 & $11,80 \pm 0,49$ & $11,90 \pm 0,80$ & $10,80 \pm 0,50$ & $10,80 \pm 1,47$ & $10,90 \pm 1,04$ & $11,10 \pm 0,92$ \\
\hline G 2 & $10,30 \pm 2,56$ & $10,00 \pm 2,54$ & $11,20 \pm 2,92$ & $10,10 \pm 1,85$ & $10,60 \pm 2,73$ & $11,00 \pm 2,30$ \\
\hline G 3 & $12,00 \pm 1,75$ & $10,90 \pm 1,11$ & $12,30 \pm 0,82$ & $12,20 \pm 1,57$ & $10,90 \pm 0,81$ & $10,80 \pm 0,65$ \\
\hline \multicolumn{7}{|r|}{ - } \\
\hline G 1 & $32,6 \pm 1,1 \mathrm{Aa}$ & $32,2 \pm 1,1 \mathrm{Aa}$ & $31,4 \pm 1,3 \mathrm{Aa}$ & $30,6 \pm 1,6 \mathrm{Aa}$ & $26,4 \pm 5,5 \mathrm{Aa}$ & $29,0 \pm 1,0 \mathrm{Aa}$ \\
\hline G 2 & $35,2 \pm 2,0 \mathrm{Aa}$ & $34,6 \pm 4,3 \mathrm{Aa}$ & $34,6 \pm 3,2 \mathrm{Aa}$ & $35,8 \pm 3,5 \mathrm{Aa}$ & $39,2 \pm 2,5 \mathrm{Ab}$ & $39,8 \pm 2,4 \mathrm{Ab}$ \\
\hline \multirow{2}{*}{\multicolumn{7}{|c|}{$\mathrm{Le} / \mu 1\left(\mathrm{x} 10^{3}\right)$}} \\
\hline & & & & & & \\
\hline G 1 & $9,2 \pm 0,7 \mathrm{Aa}$ & $9,3 \pm 0,9 \mathrm{Aa}$ & $9,4 \pm 0,6 \mathrm{Aa}$ & $8,7 \pm 1,1 \mathrm{Aa}$ & $9,9 \pm 1,2 \mathrm{Aa}$ & $9,2 \pm 1,3 \mathrm{Aa}$ \\
\hline G 2 & $11,4 \pm 2,0 \mathrm{Aa}$ & $11,5 \pm 1,7 \mathrm{Aa}$ & $11,8 \pm 1,5 \mathrm{Aa}$ & $13,1 \pm 2,3 \mathrm{Aab}$ & $13,0 \pm 5,9 \mathrm{Aa}$ & $16,0 \pm 5,0 \mathrm{Ab}$ \\
\hline G 3 & $11,2 \pm 2,2 \mathrm{Aa}$ & $11,3 \pm 1,5 \mathrm{Aa}$ & $11,8 \pm 1,2 \mathrm{Aa}$ & $15,2 \pm 5,4 \mathrm{ABb}$ & $18,9 \pm 5,9 \mathrm{Bb}$ & $19,2 \pm 5,4 \mathrm{Bb}$ \\
\hline \multicolumn{7}{|l|}{$\begin{array}{l}\mathrm{Plaq} / \mu \mathrm{l} \\
\left(\mathrm{x} 10^{3}\right)\end{array}$} \\
\hline G 1 & $226,0 \pm 20,3$ & $214,0 \pm 20,7$ & $227,2 \pm 13,6$ & $225,2 \pm 35,0$ & $238,0 \pm 27,4$ & $201,6 \pm 21,2$ \\
\hline G 2 & $223,8 \pm 79,8$ & $247,7 \pm 109,1$ & $279,3 \pm 38,3$ & $267,1 \pm 74,8$ & $189,4 \pm 60,4$ & $165,1 \pm 81,2$ \\
\hline G 3 & $261,0 \pm 57,1$ & $228,0 \pm 29,6$ & $242,0 \pm 44,8$ & $217,0 \pm 11,7$ & $210,0 \pm 33,7$ & $232,0 \pm 24,7$ \\
\hline \multicolumn{7}{|l|}{ PT (g/dl) } \\
\hline G 1 & $7,88 \pm 0,41 \mathrm{Aa}$ & $8,00 \pm 0,45 \mathrm{Ab}$ & $7,68 \pm 0,46 \mathrm{Aab}$ & $7,64 \pm 0,48 \mathrm{Aa}$ & $7,44 \pm 0,59 \mathrm{Aa}$ & $7,44 \pm 0,59 \mathrm{Aa}$ \\
\hline G 2 & $7,52 \pm 1,07 \mathrm{Aa}$ & $6,80 \pm 0,71 \mathrm{Aa}$ & $7,00 \pm 0,88 \mathrm{Aa}$ & $7,08 \pm 0,73 \mathrm{Aa}$ & $7,28 \pm 1,03 \mathrm{Aa}$ & $7,36 \pm 0,96 \mathrm{Aa}$ \\
\hline G 3 & $8,16 \pm 0,57 \mathrm{Aa}$ & $8,00 \pm 0,85 \mathrm{Ab}$ & $8,40 \pm 0,87 \mathrm{Ab}$ & $9,00 \pm 1,67 \mathrm{Ab}$ & $8,20 \pm 1,21 \mathrm{Aa}$ & $8,20 \pm 1,10 \mathrm{Aa}$ \\
\hline \multicolumn{7}{|l|}{ FIB (mg/dl) } \\
\hline G 1 & $0,40 \pm 0,09$ & $0,30 \pm 0,11$ & $0,40 \pm 0,22$ & $0,40 \pm 0,17$ & $0,40 \pm 0,17$ & $0,40 \pm 0,09$ \\
\hline G 2 & $0,32 \pm 0,10$ & $0,28 \pm 0,10$ & $0,32 \pm 0,18$ & $0,28+0,18$ & $0,4 \pm 0,24$ & $0,36 \pm 0,17$ \\
\hline G 3 & $0,32+0,10$ & $0,24+0,099$ & $0,32+0,10$ & $0,32+0,10$ & $0,36+0,09$ & $0,32+0,10$ \\
\hline
\end{tabular}

GI: grupo controle; GII: grupo tratado com 17,6g de amido de milho; GIII: idem ao GII + administração de heparina; He: hemácias; Hb: hemoglobina; Ht: hematócrito; Le: leucócitos, Plaq: plaquetas; Pt: proteína total; FIB: fibrinogênio.

Letras maiúsculas diferentes indicam diferenças entre grupos pelo teste Tukey $(\mathrm{P}<0,05)$.

Letras minúsculas diferentes indicam diferenças entre momentos pelo teste Tukey $(\mathrm{P}<0,05)$.

\section{DISCUSSÃO}

A indução experimental de laminite por sobrecarga alimentar de carboidratos teve êxito em $100 \%$ dos 10 eqüinos submetidos ao modelo experimental descrito por Obel (1948), à semelhança do constatado por Eades et al. (2006) e Souza (2007). O tempo necessário para a manifestação de laminite grau III foi de 36 horas, semelhante ao descrito por Garner et al. (1975).

Os parâmetros clínicos e laboratoriais obtidos durante a fase prodrômica, assim como no início da fase aguda da laminite, sugerem a ocorrência de graves alterações hemodinâmicas, supostamente devido à complexa patogenia da laminite, a qual muito se assemelha aos mecanismos intermediários da hipertensão sistêmica (Garner et al., 1975), da síndrome do choque e da coagulação intravascular disseminada (Thomassian et al., 2000). Os primeiros sinais de claudicação apresentados pelos eqüinos dos grupos II e III, ocorreram $12 \mathrm{e}$ 24 horas após a administração de carboidratos, respectivamente. Inicialmente, notou-se troca de apoio intermitente do membro e, posteriormente, sinais de sensibilidade ao caminhar, que evoluíram para claudicação severa e relutância em caminhar. O quadro clínico e a evolução foram semelhantes aos descritos por Obel (1948).

Os eqüinos dos grupos II e III apresentaram aumento da freqüência cardíaca em momentos 
semelhantes aos relatados por Garner et al. (1975), mas elevações significativas foram notadas apenas a partir de 36 horas após o fornecimento de carboidratos, possivelmente devido à dor e/ou insuficiência cardiovascular decorrentes do aumento da viscosidade sanguínea e dos distúrbios na circulação periférica. $\mathrm{O}$ tempo de preenchimento capilar dos eqüinos dos grupos II e III elevou-se 24 horas após a indução de laminite, porém alterações significativas foram notadas apenas no grupo III, a partir de 36 horas após o início do experimento. Além das alterações na flora cecal e conseqüente liberação de endotoxinas, a administração de grande volume de carboidratos aumenta a osmolalidade do fluido cecal, causando desvio de líquido dos compartimentos extra e intravascular para o lúmem intestinal. Esse mecanismo pode contribuir no desequilíbrio hidroeletrolítico e na redução do volume plasmático. Esses eventos auxiliam a compreensão das alterações da freqüência cardíaca e do tempo de preenchimento capilar.

Alterações não significativas na qualidade e freqüência do pulso da artéria maxilar externa foram observadas a partir de 24 horas após a administração de carboidratos, nos eqüinos dos grupos II e III. Estudos relatam que vasoconstrição (Moore et al., 1989; Baxter, 1994) e microtrombose (Weiss et al., 1994) estão relacionadas com a degeneração laminar decorrente de laminite. Relatam, também, elevação da pressão venosa, da pressão hidrostática e alteração do fluxo sangüíneo, tornando o pulso digital cheio e forte. $\mathrm{O}$ pulso arterial digital dos eqüinos do grupo II elevou-se 48 horas após o início da fase experimental, alteração observada com menor intensidade nos animais do grupo III, possivelmente pela ação da heparina.

Elevações significativas na temperatura retal foram observadas 36 e 24 horas após a administração de carboidratos, nos eqüinos dos grupos II e III, respectivamente, possivelmente devido ao crescimento exponencial da microbiota cecal e conseqüente liberação de substâncias pirogênicas, conforme relatos de Garner et al. (1975). Além de alterações na flora cecal e conseqüente liberação de endotoxinas, a degradação microbiana do carboidrato produz grande quantidade de ácido láctico, aumentando a osmolalidade do líquido cecal e atraindo fluidos para o lúmem intestinal, causando amolecimento e liquefação das fezes. Embora este sinal clínico tenha sido detectado neste trabalho, as oscilações na motilidade intestinal dos animais dos grupos II e III não foram estatisticamente significativas.

Foram constatadas oscilações não significativas na freqüência respiratória dos eqüinos do grupo II, possivelmente conseqüentes à acidose metabólica (Garner et al., 1975) e/ou ao aumento da sensibilidade podal, sinal observado precocemente na presente pesquisa.

O volume globular dos animais dos grupos II se alterou significativamente a partir de 36 horas do início do experimento em decorrência das alterações hemodinâmicas já descritas. Weiss et al. (1997a), ao utilizar doses de heparina sódica próximas às empregadas neste trabalho, notou aglutinação de hemácias, anemia e trombocitopenia temporárias. Tais alterações não foram observadas no presente estudo. Constatouse discreto aumento da contagem de leucócitos dos animais dos grupos II e III a partir de 24 horas do início do período experimental. Embora se constatem elevações progressivas no decorrer do experimento, alterações significativas ocorreram apenas às 48 horas nos do grupo II e, às 36 horas após o fornecimento de carboidrato, nos do grupo III. Os resultados assemelham-se aos obtidos por Weiss et al. (1995; 1997a). Weiss et al. (1995) verificaram que houve ativação, seqüestro e agregação de plaquetas quando se induziu laminite em pôneis, durante as primeiras 10 horas após o fornecimento de carboidratos. Em estudo anterior, Weiss et al. (1994) haviam observado diminuição do tempo de sobrevida plaquetária e evidência cintilográfica de acúmulo de plaquetas no cório laminar de pôneis, no início da claudicação. No entanto, no presente trabalho não se verificou alteração na contagem de plaquetas que comprovasse tais afirmações.

As concentrações de fibrinogênio do plasma não apresentaram elevações significativas. Os teores de proteínas totais dos grupos II e III não se alteraram ao longo do período experimental; contudo, diferenças significativas entre os momentos foram observadas nos grupos II e III, 8 horas e entre 12 e 24 horas, respectivamente.

O uso de heparina, na prevenção da laminite aguda, foi preconizado por Hood et al. (1982). A 
utilização desse fármaco para tal fim baseou-se na constatação do aumento na concentração sangüínea de produtos da degradação de fibrina durante o desenvolvimento da afecção, bem como de microtrombos na fase aguda da laminite; esses relatos deram suporte à hipótese de que a coagulopatia é um componente da fase prodrômica de laminite (Weiss et al., 1997a). Os resultados do presente estudo indicam que os eqüinos do grupo III não apresentaram lesões histológicas menos graves que aquelas verificadas nos do grupo II; ademais, na posologia utilizada, a heparina não impediu o desenvolvimento de laminite, embora os animais do grupo III tenham apresentado melhor qualidade de pulso.

A estreita relação entre as alterações histológicas e os sinais clínicos observados na laminite aguda pode propiciar informações importantes para o entendimento da fisiopatogenia da degeneração laminar. Algumas hipóteses foram aventadas para justificar a isquemia e a hipoperfusão, eventos que precedem a degeneração laminar. $\mathrm{O}$ menor fluxo sanguíneo às lâminas do casco se deve à venuloconstrição (Baxter, 1994) ou à formação de microtrombos em veias (Weiss et al., 1994). Há outros postulados que diferem dessas teorias como o de Trout et al. (1990) que sugere o desvio de sangue pelas anastomoses arteriovenosas como causa da menor perfusão laminar. Pollitt et al. (1998), Johnson et al. (2000) e Allen (2004) atribuíram a degeneração da membrana basal e a conseqüente destruição das lâminas dérmicas e epidérmicas à ação de metaloproteinases.

Nos animais do grupo III, as alterações histológicas foram indistinguíveis das observadas nos do grupo II e restringiam-se às do tipo degenerativo. A análise histológica do tecido lamelar do casco revelou que os eqüinos apresentaram ampla variedade de lesões, como adelgaçamento das lâminas epidérmicas primárias e secundárias, retração, achatamento e deslocamento das lâminas dérmicas, vacuolização epidérmica, picnose nuclear, congestão vascular e desorganização do tecido epidérmico. Outras anormalidades foram mais evidentes na coloração com ácido periódico de Schiff, como a degeneração da membrana basal. Foi possível notar interrupções ou fragmentações dessa membrana, semelhantes às relatadas por Pollitt (1996). Aliás, Pollitt et al. (1998) aventaram a possibilidade de degeneração da membrana basal ocorrer como conseqüência da ação de metaloproteinases ativadas e, essa ação ser o fator desencadeador de laminite.

O aparecimento de espaços vazios entre as lâminas epidérmicas secundárias foi outra alteração histológica observada neste estudo. Resultados semelhantes foram relatados por Allen (2004) e Souza (2007), que encontraram nessas lesões evidências de edema. A formação de edema decorrente do aumento da pressão hidrostática capilar, reportada em trabalhos sobre a hemodinâmica do casco de eqüinos portadores de laminite, constitue a base teórica que atribui o desenvolvimento de laminite à venuloconstrição (Baxter, 1994; Allen, 2004). Entretanto, uma explicação alternativa é a de que as células basais da epiderme separam-se da membrana basal e, segundo Pollitt (1996), simplesmente deixam as lâminas dérmicas secundárias com pouca quantidade de tecido conectivo, aparecendo histologicamente como espaços vazios. Os relatos deste estudo são semelhantes aos observados por esse autor, descritos como retrações do tecido dérmico, que estavam, freqüentemente, associados à ruptura ou fragmentação da membrana basal, nitidamente sem a presença de fluido. Segundo Pollitt (1996), esses espaços podem ser preenchidos por gases ou ar e ocasionam o aparecimento de uma linha radioluscente no aspecto palmar das lâminas do casco no exame radiográfico, no caso de laminite aguda. A não evidência histológica de edema indica que a resposta vascular dos animais com laminite é normal e, que a formação de edema não está envolvida na fisiopatogenia da laminite aguda.

Embora relatada na literatura, a presença de células inflamatórias nos ápices das lâminas dérmicas e ao redor dos vasos não foi um achado freqüente nas secções avaliadas, reforçando a afirmação de Moore et al. (1989), que o termo mais apropriado para essa enfermidade seria "degeneração laminar aguda". Ocasionalmente, na derme sublamelar, foram identificados vasos sangüíneos, inclusive capilares, contendo material proteináceo amorfo corado em rosa, indicando trombose. Tal ocorrência não se assemelha em quantidade e freqüência aos resultados descritos por Weiss et al. (1994). 
A administração de heparina aos animais do grupo III não preveniu ou atenuou a degeneração laminar, as quais se assemelharam àquelas notadas nos eqüinos do grupo II. Este fato sugere que outras causas, além das alterações nos mecanismos de coagulação e conseqüente microtrombose, podem estar relacionadas à patogenia da laminite.

\section{CONCLUSÕES}

As alterações histológicas observadas poucas horas após o desenvolvimento da fase aguda da laminite permitem inferir que qualquer terapia com intuito de prevenir laminite deve ser empregada antes da manifestação de claudicação. A administração de heparina, na dose utilizada neste trabalho, não foi capaz de impedir o desenvolvimento de laminite aguda, tampouco de alterações degenerativas do tecido dérmico e epidérmico de eqüinos submetidos à indução experimental de laminite por sobrecarga de carboidratos.

\section{AGRADECIMENTOS}

Agradecemos à FAPESP pelo auxílio financeiro.

\section{REFERÊNCIAS BIBLIOGRÁFICAS}

ALLEN, D.J. Overview of pathogenesis of laminitis: models and theories. In: EQUINE LAMINITIS RESEARCH MEETING AND PANEL, 2004, Louisville. Proceedings..., Louisville: AAEP, 2004. p.9-23.

BAILEY, S.R.; MARR, C.M.; ELLIOT, J. Current research and theories on the pathogenesis of acute laminitis in the horse. $B r$. Vet. J., v.167, p.129-142, 2004.

BAXTER, G.M. Acute laminitis. Vet. Clin. N. Am., v.3, p.627-642, 1994.

COHEN, N.D.; PARSON, E.M.; SEAHORN, T.L. et al. Prevalence and factors associated with development of laminitis in horses with duodenitis/proximal jejunitis: 33 cases (19851991). J. Am. Vet. Med. Assoc., v.204, p.250254, 1994.

EADES, S.C.; STOKES, A.M.; MOORE, R.M. Effects of an endothelin receptor antagonist and nitroglycerin on digital vascular function in horse during the prodromal stages of carbohydrate overload-induced laminitis. Am. J. Vet. Res., v.67, p.1204-1211, 2006.

FAGLIARI, J.J.; McCLENAHAN, D.; WEISS, D.J. et al. Changes in plasma protein concentrations in ponies with experimentally induced alimentary laminitis. Am. J. Vet. Res., v.59, p.1234-1237, 1998.

GARNER, H.E.; COFFMAN, J.R.; HAHN, A.W. et al. Arterial pressure, cardiac output, plasma volume and L-lactate changes in equine laminitis. Phisiologist, v.18, p.224-229, 1975.

HOOD, D.M.; STEPHENS, K.A.; AMOSS, M.S. Heparin as a preventive for equine laminitis. In: EQUINE ENDOTOXEMIA LAMINITIS SYMPOSIUM, 1., 1982, Lexington. Proceedings..., Lexington, 1982. p.146-149.

HOOD, D.M.; GROSENBAUGH, D.A.; MOSTAFA, M.B. et al. The role of vascular mechanisms in the development of acute laminitis. J. Vet. Intern. Med., v.7, p.228-234, 1993.

JOHNSON, P.J.; KREEGER, J.M.; KEELER, M. et al. Serum markers of lamellar basement membrane degradation and lamellar histopathological changes in horses affectd whith laminitis. Equine Vet. J., v.32, p.462-468, 2000.

MOORE, J.N.; ALLEN, J.D.; CLARK, E.S. Pathophysiology of acute laminitis. Vet. Clin. N. Am.: Equine Pract., v.5, p.67-72, 1989.

OBEL, N. (Ed). Studies on the histopathology of acute laminitis. Stockholm: Vet. Stockholm, 1948. p.1-50.

POLLITT, C.C. Basement membrane pathology: a feature of acute equine laminitis. Equine Vet. J., v.28, p.38-46, 1996.

POLLITT, C.C.; PASS, M.A.; POLLITT, S. Batimast (BB - 94) inhibits matrix metalloproteinases of equine laminitis. Equine Vet. J., v.30, suppl.27, p.119-124, 1998.

POLLITT, C.C. A revised pathophysiology. Am. Assoc. Equine Pract. Proc., v.45, p.188-192, 1999.

SOUZA, A.H. Tamponamento cecal: aspectos clínico, fisiopatológico e terapêutico na laminite experimental, em eqüinos. 2007. 219f. Tese (Doutorado) - Faculdade de Ciências Agrárias e Veterinárias, Universidade Estadual Paulista, Jaboticabal. 
SPEIRS, C.V. (Ed). Clinical examination of horses. Pennsylvania: Saunders, 1996. 358p.

THOMASSIAN, A.; NICOLETTI, J.L.M.; HUSSNI, C.A. et al. Patofisiologia e tratamento da pododermatite asséptica difusa nos eqüinos (Laminite Eqüina). Rev. Educ. Cont., v.3, p.1629, 2000.

TROUT, D.R.; HORNOF, W.J.; LINFORD, R.L. et al. Scintigraphic evaluation of digital circulation during the developmental and acut phases of equine laminitis. Equine Vet. J., v.22, p.416-421, 1990.

USER's guide: statistics. Version 6.2. Cary: SAS Institute, 1995.

WEISS, D.J.; GEOR, R.J.; JOHNSTON, G. et al. Microvascular thrombosis associated with the onset of acute laminitis in ponies. Am. J. Vet. Res., v.55, p.606-612, 1994.
WEISS, D.J.; TRENT, A.M.; JOHNSTON, G. Prothrombotic events in the prodromal stages of acute laminitis in horses. Am. J. Vet. Res., v.56, p.986-991, 1995.

WEISS, D.J.; McCLENAHAM, D.; FAGLIARI, J.J. et al. Evaluation of platelet activation and platelet-neutrophil aggregates in ponies with alimentary laminitis. Am. J. Vet. Res., v.58, p.1431-1434, 1997a.

WEISS, D.J.; McCLENAHAM, D.; FAGLIARI, J.J. et al. A preliminary study of mucosal barrier function in experimental equine laminitis. Vet. Pathol., v.34, p.480, 1997 b.

WEISS, J.D.; EVANSON, O.A.; FAGLIARI, J.J. et al. Haemorrheology of equine plateletneutrophil aggregates. Am. J. Vet. Res., v.9, p.5559, 1999. 